\title{
Maternal physiological changes at rest induced by exercise during pregnancy: A randomized controlled trial
}

\author{
Irene Fernández-Buhigas ${ }^{\mathrm{a}, \mathrm{b}, 1, *}$, Maia Brik ${ }^{\mathrm{a}, \mathrm{b}, \mathrm{d}, 1}$, Aranzazu Martin-Arias ${ }^{\mathrm{a}, \mathrm{b}}$, Marina Vargas-Terrones ${ }^{\mathrm{c}}$, \\ David Varillas $^{\mathrm{b}}$, Rubén Barakat ${ }^{\mathrm{c}}$, Belén Santacruz ${ }^{\mathrm{a}, \mathrm{b}}$ \\ a Obstetrics Department, Hospital Universitario de Torrejon, Madrid, Spain \\ b Faculty of Medicine, Pozuelo de Alarcón, Universidad Francisco de Vitoria, Madrid, Spain \\ ${ }^{c}$ AFIPE Research Group, Faculty of Sciences for Physical Activity and Sport, INEF, Universidad Politécnica de Madrid (UPM), Madrid, Spain \\ d Maternal Fetal Medicine Department. Hospital Universitari Vall d'Hebron. Universitat Autonoma de Barcelona. Barcelona, Spain
}

\section{A R T I C L E I N F O}

\section{Keywords}

Pregnancy

Exercise

Blood pressure

Glucose

Hepatic enzymes

Uric acid

\begin{abstract}
A B S T R A C T
Objective: to analyse maternal physiological changes in several areas (cardiovascular, metabolic, renal and hepatic) related to the regular practice of a supervised exercise program.

Methods: This is an unplanned secondary analysis from a randomized controlled trial carried out in a single maternity unit in Madrid, Spain (NCT 02,756,143). From November 2014 to June 2015, 92 women were randomly assigned to perform a mild-moderate supervised exercise program during pregnancy (Intervention group, IG) or to continue with their routine pregnancy care (control group, CG). For the purpose of this study we collected clinical and analytical data (heart blood pressure, weight, blood glucose, AST, ALT, blood Creatinine and blood Uric acid) available from all obstetric visits and examined the differences between groups.

Results: We did not find any differences in: pregnancy weight (IG: $11.4 \pm 4.4 \mathrm{Kg}$ vs. CG: $10.1 \pm 5.3 \mathrm{Kg}$; $p=0.173$ ); fasting glucose at $10^{+0}-12^{+6}$ weeks (IG: $78.48 \pm 8.34$ vs. CG: $76 \pm 13.26, p=0.305$ ) or at $34^{+0}-36^{+4}$ weeks (IG: $73.25 \pm 10.27$ vs CG: $73.45 \pm 8.29, p=0.920$ ), and 50 gs glucose tolerance at $24^{+4}-26^{+6}$ weeks (IG: $116.23 \pm 35.07$ vs CG: $116.36 \pm 25.98, p=0.984$ ); Aspartate-amino-transferase at $10^{+0}-12^{+6}$ weeks (IG: $15.38 \pm 4.17$ vs CG: $17.33 \pm 7.05, p=0.124$ ) and at $34^{+0}-36^{+4}$ weeks (IG: $21.65 \pm 5.25$ vs $C G: 19.53 \pm 8.32, p=0.165$ ) or Alanine-amino- transferase at $10^{+0}-12^{+6}$ weeks (IG: $27.50 \pm 10.63$ vs CG: $28.27 \pm 11.77, p=0.746$ ) or at $34^{+0}-36^{+4}$ weeks (IG: $22.93 \pm 9.23$ vs CG: $20.84 \pm 13.49$, $p=0.407$ ); blood Creatinine concentrations at $34^{+0}-36^{+4}$ weeks (IG: $0.595 \pm 0.401$ vs CG: $0.575 \pm 0.100$, $p=0.757$ ) and blood uric acid concentrations at $34^{+0}-36^{+4}$ weeks (IG: $3.526 \pm 0.787$ vs CG: $3.262 \pm 0.672$, $p=0.218$ ). Heart blood pressure was similar between groups except at $27^{+0}-28^{+6}$ weeks, where systolic blood pressure was significantly lower in the CG in comparison to the IG $(116.31 \pm 10.8 \mathrm{mmHg}$ vs. $120.22 \pm 10.3 \mathrm{mmHg}, p=0.010$ ).

Conclusion: Regular supervised exercise during pregnancy does not alter normal maternal physiology.
\end{abstract}

\section{Introduction}

Regular exercise mediates several physiological modifications in the human being, contributing to the prevention of several illnesses and to the personal wellbeing. In order to prevent obesity and several cardiovascular and metabolic illness, the World Health Organization (WHO) has published a guideline proposing the minimal activity recommended according to ages [1].

Cardiovascular changes at rest have been described in pregnant women that are under a supervised mild-moderate exercise program during pregnancy, like lower heart rate levels or lower heart blood systolic and diastolic pressures [2-5]. This would reflect a positive adaptation of the maternal cardiovascular system to the exercise and it may reduce the risk of preeclampsia during pregnancy [6].
Regarding metabolism, a good supply of nutrients is essential during pregnancy [7]. Exercise increases the use of glucose by the muscles, and it has been shown that a decrease in the blood glucose just occurs for a short period of time during prenatal exercise and, more acutely during the third trimester. Additionally, exercise during pregnancy elevates circulating triglyceride levels [8]. It has been reported that acute exercise in pregnant women, as opposed to choric exercise training, is associated with increased sympatho-adrenal and neurohumoral activity[7,9]. On the other hand, regular exercise, during pregnancy reduces glucose levels at the screening test for gestational diabetes ( 50 gs Glucose Tolerance Test) at 24-28 weeks of gestation [10]. At renal level, no effect has been concluded when performing moderate exercise during pregnancy [8].

Most studies conclude that the regular practice of mild to moderate exercise during pregnancy is not only safe but even positive for both, the mother and 
the future new-born [4], although the underlying physiological changes are not well established.

The aim of the present study was to analyse physiological changes in the maternal cardiovascular, metabolic, renal and hepatic systems, in relation to the regular practice of a supervised mild-moderate exercise program. We hypothesized that this exercise during pregnancy would not alter the normal maternal physiology.

\section{Methods}

\subsection{Trial design and participants}

This is an unplanned secondary analysis of a randomized controlled trial (RCT), performed at the Hospital Universitario de Torrejon, Madrid, Spain (NCT 02,756,143). A complete description of the design and methods of this RCT, was recently published [11]. Our main Objective was to clarify if performing a supervised controlled exercise program throughout pregnancy prevented excessive gestational weight gain. From November 2014 to June 2015, we included a total of 124 pregnant women.

Inclusion criteria were: (I) no obstetric complications according to the American College of Obstetricians and Gynaecologists (ACOG) guidelines [12], (II) gestational age at recruitment $<16$ weeks, (III) not exercising regularly for more than $30 \mathrm{~min}$ (3 days per week), and (IV) able to communicate in Spanish. Exclusion criteria were non-availability to attend to the exercise program during pregnancy or not full filling any of the inclusion criteria.

A simple randomisation was performed with the Epidat V.3.1 program to allocate the participants into two groups in order of entry: intervention group (IG) and control group (CG). For this, a computer-generated list of random numbers $(n=200)$ was created through the Epidat option of balanced groups (similar but not of equal size). Unfortunately, due to the lack of resources, the target number of participant could not be achieved.

Trial coordinators regularly undertook quality control of data handling, and verification of adherence to protocols.

The study was approved by the Local Research Ethics Committee (CEIm Hospital Universitario Severo Ochoa) (19/07/2013). All women gave written consent.

\subsection{Maternal and pregnancy characteristics}

We recorded the following maternal characteristics: maternal age, maternal weight at $12^{+0}-13^{+5}$ weeks and height, Body mass index (BMI), racial origin (Caucasian vs non-Caucasian), method of conception (natural or assisted conception), cigarette smoking during pregnancy (yes or no), parity (parous or, according to previous delivery at $\geq 24$ weeks' gestation) and gestational age at delivery in days from the last menstrual period calculated by ultrasound.

\subsection{Control group}

Pregnant women allocated to the CG were advised to do normal daily activity and not to join any educational exercise program including more than 30 min per day at least 3 times per week. The weekly volume of physical activity was monitored by an exercise specialist at a final interview at $38^{+0}-39^{+6}$ weeks of gestation.

\subsection{Intervention programme}

The intervention programme was designed according to the 2015 ACOG standards and followed the structure of previous programme studies [12-15]. It consisted in a supervised physical conditioning programme of three-60-minutes-sessions per week during the whole pregnancy (from $12^{+3}-15^{+6}$ weeks to $38^{+0}-39^{+6}$ weeks of gestation) at the Hospital gym. Women could attend any of the two evening sessions we offered four days per week, up to a total of three. Each session included $10 \mathrm{~min}$ of warming up, $25 \mathrm{~min}$ of cardiovascular exercise, $10 \mathrm{~min}$ of strengthening exercises, $5 \mathrm{~min}$ of coordination and balance, $5 \mathrm{~min}$ of pelvic floor exercises and $5 \mathrm{~min}$ of stretching and relaxation. Exer- cises in the supine position were not performed for more than $2 \mathrm{~min}$. Aerobic activity was prescribed at mild to moderate intensity, aiming for $55-60 \%$ of maximum heart rate (HR). All women wore a HR monitor (Polar FT7) during the training session to ensure that exercise intensity was mild-moderate and the rating of perceived exertion scale ranged from 12 to 14 (Somewhat Hard) [16].

Weekly volume of physical activity and the percentage of assistance to the program were monitored all throughout the pregnancy by a qualified exercise specialist trained in pre and postnatal exercise.

\subsection{Follow-up}

Once recruited, both groups had a similar follow-up at the Hospital Universitario de Torrejon. Obstetric appointment took place at $12^{+0}-13^{+5}, 19^{+0}-21^{+6}, 27^{+0}-28^{+6}$ and $35^{+0}-36^{+6}$ weeks of gestation. Maternal blood pressure and maternal weight were checked in every visit. Measurements taken at $12^{+0}-13^{+5}$ week's appointment were considered as the baseline measurements. Patients were randomized until $15^{+6}$ weeks of gestation. All patients had a final interview with the exercise specialist at $38^{+0}-39^{+6}$ weeks' gestation in other to check their final weight and assess weekly volume of physical activity.

Routine blood routine tests were performed fasting at $10^{+0}-12^{+6}$ and $34^{+0}-36^{+4}$ weeks, and not fasting at $24^{+4}-26^{+6}$ weeks, always in the morning.

Microlife WatchBP Home blood pressure monitor was used for blood pressure assessment. Blood pressure was measured after $5 \mathrm{~min}$ of rest in a sitting position, with the arm resting at the level of the heart. Maternal weight was measured in an automatic SECA scale. Blood samples for glucose, Aspartate-amino-transferase (AST), Alanine-amino-transferase (ALT), creatinine and uric acid, were analysed by Dimension EXL (Siemens).

\subsection{Study outcomes}

Study outcomes were verified by one of three members of the research team (I.F.B., M.B. or A.M.) and are summarized in the following list according to the organ studied.

\subsubsection{Cardiovascular}

Maternal systolic and diastolic blood pressure measured in $\mathrm{mmHg}$, after $5 \mathrm{~min}$ of rest, in sitting resting position, in one arm at heart level, checked at $12^{+0}-13^{+5}$ (baseline), $19^{+0}-21^{+6}, 27^{+0}-28^{+6}$ and $35^{+0}-36^{+6}$ weeks in the obstetric appointment.

\subsubsection{Metabolic and hepatic}

Maternal weight measured $(\mathrm{Kg})$, checked at $12^{+0}-13^{+5}$ (baseline), $19^{+0}-21^{+6}, 27^{+0}-28^{+6}, 35^{+0}-36^{+6}$ and at $38^{+0}-39^{+6}$ (final weight). Pregnancy weight gain was calculated as the final maternal weight minus the baseline weight.

Fasting blood glucose levels $(\mathrm{mg} / \mathrm{dl})$ were measured at the $10^{+0}-12^{+6}$ - and $34^{+0}-36^{+4}$ weeks routing blood tests. Blood glucose levels $60 \mathrm{~min}$ after a $50 \mathrm{mg}$ Glucose Tolerance Test were measured at the $24^{+4}-26^{+6}$ weeks routine blood test.

Alanine-amino-transferase (ALT) and Aspartate-amino-transferase (AST) were measured at the $10^{+0}-12^{+6}$ and $34^{+0}-36^{+4}$ weeks routine blood test (UI/l) to asses hepatic function and amnio acid metabolism, respectively.

\subsubsection{Renal}

Serum creatinine and uric acid levels $(\mathrm{mg} / \mathrm{dl})$ were determined at the $34^{+0}-36^{+4}$ weeks routine blood test to asses renal function. Our protocol did not include any earlier analysis.

\subsection{Statistical analysis}

To describe demographic and clinical characteristics of patients, data were expressed as mean (standard deviation) or median (interquartile range), and proportions (absolute and relative frequencies) as appropriate. Comparisons between treatment groups were performed by 
ware package SPSS (IBM Corp. Released 2012. IBM SPSS Statistics for Windows, Version 21.0. Armonk, NY: IBM Corp) was used for data analysis.

\section{Results}

A total of 124 women were recruited and randomized into two groups. Seventy pregnant women were randomised to the intervention group (IG) and 54 to de control group (CG). Three women were excluded from the CG: one woman because of a late miscarriage at 20 weeks, other because of high-risk pregnancy (anti-kell antibodies), and the third one withdrew consent after randomization. Additionally, one woman from the IG had non available blood tests results. Twenty-eight women from IG were not compliant with the programme and attended $<70 \%$ of the programme as requested by the study protocol. A per protocol analysis was finally made with the two final groups: IG $(N=41)$ and CG $(N=51)$, as shown in the Trial Profile (Fig. 1$)$.

The baseline characteristics were similar in both groups. Regarding maternal age, pre-pregnancy BMI, parity, IVF pregnancy, ethnic, previous to pregnancy physical exercise and smoking, both groups were homogeneous (Table 1).

\subsection{Cardiovascular outcomes}

Both systolic and diastolic blood pressure were studied (Table 2) and no differences were found except at 28 weeks, were systolic blood pressure was lower in the CG compared to the IG $(116.31 \pm 10.8 \mathrm{mmHg}$ vs. $120.22 \pm 10.3 \mathrm{mmHg}, p=0.010$ ), but always within normal ranges.

\subsection{Metabolic and hepatic outcomes}

The evolution through gestation of the maternal weight was analysed and no differences were found between groups (Table 3).

When analysing maternal weight gain during pregnancy, no difference was found. However, there was a tendency for a lower maternal weight at the end of the pregnancy in the IG compared to the CG (10.1 $\pm 5 \mathrm{Kg}$ vs. $11.4 \pm 4 \mathrm{Kg}, p=0.173$ ) (Table 3 ).

Fasting blood glucose level in the first and third trimester, blood glucose after $50 \mathrm{mg}$ glucose tolerance test, AST and ALT levels were similar in both groups (Table 3 ).

\subsection{Renal outcomes}

Creatinine and uric acid concentrations in the third trimester were similar in both groups (creatinine $0.57 \pm 0.1 \mathrm{mg} / \mathrm{dl}$ in the IG compared to $0.59 \pm 0.4 \mathrm{mg} / \mathrm{dl}$ in the CG, $p=0.757$; uric acid $3.26 \pm 0.6 \mathrm{mg} / \mathrm{dl}$ in the IG compared to $3.45 \pm 0.7 \mathrm{mg} / \mathrm{dl}$ in the $\mathrm{CG}, p=0.218$ ) (Table 3 ).

\section{Discussion}

\subsection{Main findings of the study}

In this study we found that, first renal, metabolic and hepatic metabolism was similar in pregnant women performing a moderated supervised exercise program compared to controls.

Second, although maternal blood pressure was similar between groups, systolic blood pressure was higher at $27^{+0}-28^{+6}$ weeks 'in pregnant women performing a mild-moderated supervised exercise program compared to controls.

And third, pregnancy weight gain tended to be lower in the exercise group, although we were unable to prove significance.

\subsection{Cardiovascular outcomes}

Cardiovascular changes have been described in pregnant women under a supervised exercise program during pregnancy $[17,18]$. Perales et al. [19] described that, pregnant women under a supervised mild exercise program, have significant lower heart rate levels, lower blood systolic and diastolic pressure. Moreaver, a randomized controlled study [5] found that aerobic exercise reduced resting systolic blood pressure in normotensive pregnant women and reflected a positive adaptation of the maternal cardiovascular system. Little is known about the mechanism by which exercise may reduce blood pressure during pregnancy. Exercise has been proposed to reduce oxidative stress, improve endothelial function, as well as immune and inflammatory responses $[20,21]$. In addition, exercise is associated with an increase on the cardiac output [21]. In our study we were unable to show this effect; in contrast, we found the systolic blood pressure to be higher in the IG at $27^{+0}-28^{+6}$ weeks. Since this finding sounds clinically implausible, we believe that it merely reflects the result of performing multiple comparisons, more than a real effect of the treatment, unless proven otherwise in another study.

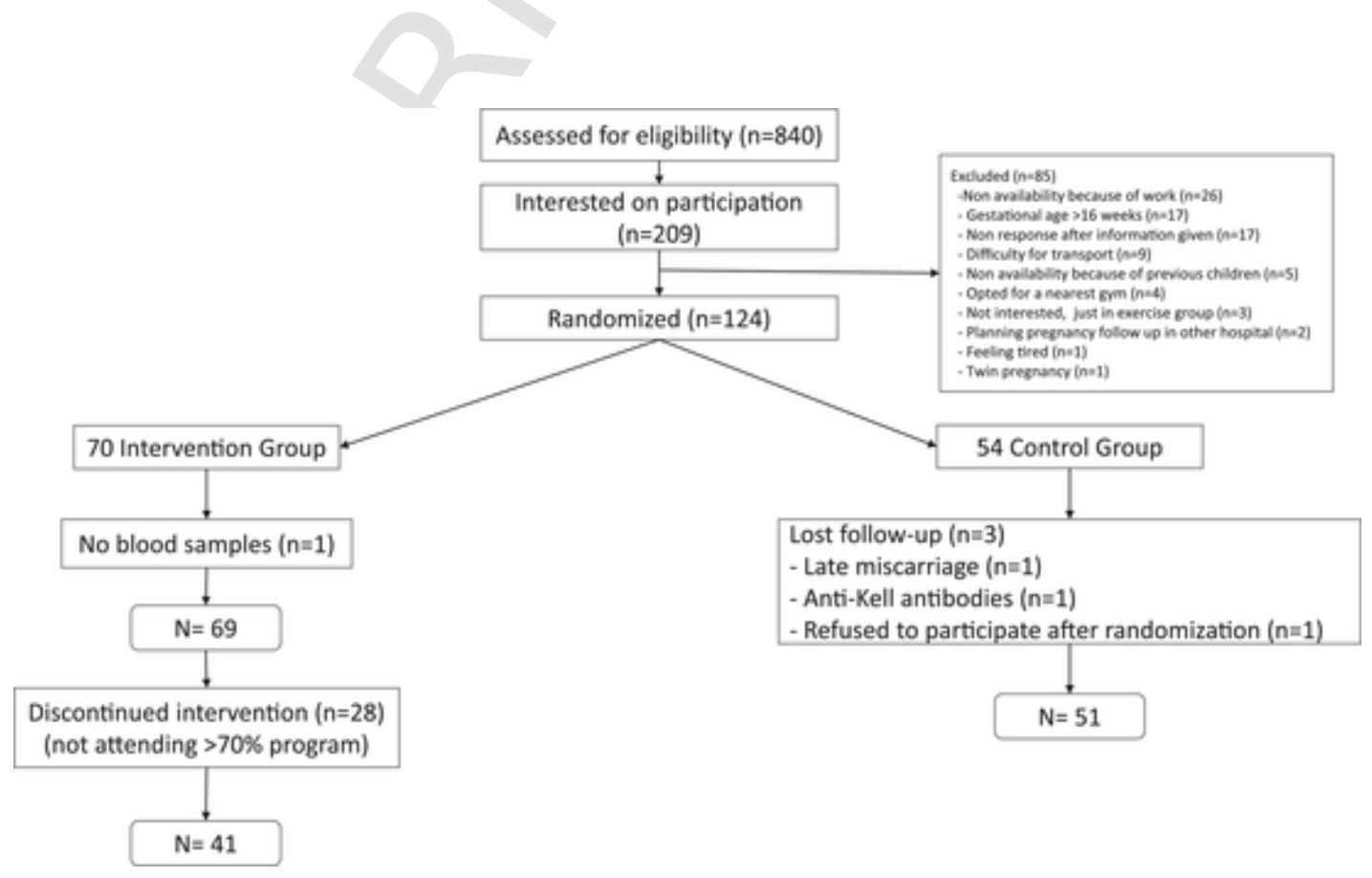

Fig. 1. Flow diagram. 
Table 1

Demographic characteristics in both groups.

Data are given as mean and Standard deviation (SD) or $\mathrm{n}(\%)$. Comparisons between outcome groups were by chi, square test for categoric variables and Mann, Whitney U test for continuous variables.

\begin{tabular}{|c|c|c|c|}
\hline & $\begin{array}{l}\text { Intervention Group } \\
(N=41)\end{array}$ & $\begin{array}{l}\text { Control Group } \\
(N=51)\end{array}$ & $\begin{array}{l}p \\
\text { value }\end{array}$ \\
\hline Maternal age (years) & 33.17 (3.19) & $32.63(4.66)$ & 0.510 \\
\hline $\begin{array}{l}\text { Maternal } 12^{+0}-13^{+5} \text { weeks } \\
\text { weight }(\mathrm{Kg})\end{array}$ & $63.65(10.90)$ & $66.10(14.56)$ & 0.380 \\
\hline Maternal height $(\mathrm{cm})$ & $164.68(6.89)$ & $164.14(5.84)$ & 0.682 \\
\hline $12^{+0}-13^{+5}$ weeks BMI & $22.81(3.54)$ & $23.80(5.09)$ & 0.293 \\
\hline IVF pregnancy & $1(2.4)$ & $2(3.9)$ & 0.611 \\
\hline Caucasian & $41(100.0)$ & $47(92.2)$ & 0.067 \\
\hline $\begin{array}{l}\text { Pre-pregnancy physical } \\
\text { exercise }\end{array}$ & $37(90.2)$ & $41(80.4)$ & 0.191 \\
\hline Nulliparous & $31(75.6)$ & $38(74.5)$ & 0.904 \\
\hline Smoking & $10(24.4)$ & $22(43.1)$ & 0.061 \\
\hline $\begin{array}{l}\text { Gestation time at delivery } \\
\text { (days) }\end{array}$ & $278.76(9.45)$ & $276.08(11.45)$ & 0.232 \\
\hline
\end{tabular}

Table 2

Cardiovascular outcomes in both groups.

Data are given as mean (Standard deviation). Comparisons between outcome groups were by chi, square test for categoric variables and Mann, Whitney $\mathrm{U}$ test for continuous variables.

\begin{tabular}{|c|c|c|c|}
\hline & \multicolumn{3}{|c|}{ Systolic Blood Pressure (mmHg) } \\
\hline & $\begin{array}{l}\text { Intervention Group } \\
(N=41)\end{array}$ & $\begin{array}{l}\text { Control Group } \\
(N=51)\end{array}$ & $p$ value \\
\hline $12^{+0}-13^{+5}$ & $120.54(10.56)$ & $119.51(11.26)$ & 0.656 \\
\hline $\begin{array}{l}\text { Week } \\
19^{+0}-21+6\end{array}$ & 123.08 (8.99) & $120.14(14.10)$ & 0.254 \\
\hline $\begin{array}{l}\text { Week } \\
27^{+0}-28^{+6}\end{array}$ & $122.20(10.31)$ & $116.31(10.80)$ & 0.010 \\
\hline \multirow[t]{3}{*}{$\begin{array}{l}\text { Week } \\
35^{+0}-36^{+6} \\
\text { Week }\end{array}$} & $121.27(8.49)$ & $119.18(14.60)$ & 0.422 \\
\hline & \multicolumn{3}{|c|}{ Diastolic Blood Pressure (mmHg) } \\
\hline & $\begin{array}{l}\text { Intervention Group } \\
(N=41)\end{array}$ & $\begin{array}{l}\text { Control Group } \\
(N=51)\end{array}$ & $\mathrm{p}$ value \\
\hline $12^{+0}-13^{+5}$ & $72.65(8.70)$ & $73.05(7.20)$ & 0.813 \\
\hline $\begin{array}{l}\text { Week } \\
19^{+0}-21+6\end{array}$ & $72.96(10.48)$ & $72.25(6.88)$ & 0.712 \\
\hline $\begin{array}{l}\text { Week } \\
27^{+0}-28^{+6}\end{array}$ & $70.92(11.03)$ & $73.12(6.90)$ & 0.269 \\
\hline $\begin{array}{l}\text { Week } \\
35^{+0}-36^{+6} \\
\text { Week }\end{array}$ & $75.33(10.81)$ & $74.46(6.31)$ & 0.653 \\
\hline
\end{tabular}

\subsection{Metabolic and hepatic outcomes}

Maternal weight gain during pregnancy has an impact on the pregnancy and on the future newborn [22-33]. Previous meta-analysis have demonstrated that exercise can help to prevent excessive weight gain during pregnancy [34-36]. In our study, no differences were found in maternal weight during each visit during pregnancy or in the maternal weight gain at the end of the pregnancy, although a tendency to a lower pregnancy weight gain could be observed in the intervention group. It is true that if we could stratify by basal BMI we may see more pronounced differences in the higher basal BMI group, as demonstrated by some studies [12,37-44], but this sub-group analysis was not possible due to the small sample size.

Glucose is essential for foetal wellbeing [7]. Exercise increases the capitation of glucose by the muscles, and therefore we could argue that the hypoglycaemia that occurs during exercising mothers may influence foetal growth or development. However, our results show no differences in the basal fasting glucose levels between groups. On the other hand, Barakat et al. [10] and Deierlein et al. [45] concluded that regular exercise during pregnancy reduces glucose levels at the screening test for
Table 3

Metabolic, Hepatic and renal outcomes in both groups.

Data are given as mean (Standard deviation). Comparisons between outcome groups were by chi, square test for categoric variables and Mann, Whitney U test for continuous variables.

\begin{tabular}{|c|c|c|c|}
\hline \multicolumn{4}{|c|}{ Weight (Kg) } \\
\hline & $\begin{array}{l}\text { Intervention Group } \\
(N=41)\end{array}$ & $\begin{array}{l}\text { Control Group } \\
(N=51)\end{array}$ & $\begin{array}{l}p \\
\text { value }\end{array}$ \\
\hline $12^{+0}-13^{+5}$ Week & 64.89 (11.15) & 64.34 (18.65) & 0.867 \\
\hline $19^{+0}-21+6$ Week & $67.96(10.66)$ & $70.11(14.50)$ & 0.430 \\
\hline $27^{+0}-28^{+6}$ Week & 71.46 (11.13) & $73.66(14.70)$ & 0.429 \\
\hline $35^{+0}-36^{+6}$ Week & $74.48(11.54)$ & 76.85 (15.05) & 0.411 \\
\hline $38^{+0}-39^{+6}$ Week & 75.15 (11.57) & 76.25 (15.47) & 0.705 \\
\hline \multirow{3}{*}{$\begin{array}{l}\text { Maternal weight } \\
\text { gain }\end{array}$} & $10.153(5.39)$ & $11.49(4.43)$ & 0.173 \\
\hline & \multicolumn{2}{|c|}{ Glucose (mg/dl) } & \\
\hline & $\begin{array}{l}\text { Interve } \\
\text { Group }\end{array}$ & $\begin{array}{l}\text { Control Group } \\
(N=51)\end{array}$ & $\begin{array}{l}p \\
\text { value }\end{array}$ \\
\hline \multirow{6}{*}{$\begin{array}{l}10^{+0}-12^{+6} \text { Week } \\
24^{+4}-26^{+6} \text { Week, } \\
\text { Glucose Tolerance } \\
34^{+0}-36^{+4} \text { Week }\end{array}$} & 78.48 & $76.00(13.26)$ & 0.305 \\
\hline & $50 \mathrm{~g}$ & $116.36(25.98)$ & 0.984 \\
\hline & Test & & \\
\hline & 73.25 & 73.45 (8.29) & 0.920 \\
\hline & \multicolumn{3}{|l|}{ AST (UI/ml) } \\
\hline & $\begin{array}{l}\text { Intervention Group } \\
(N=41)\end{array}$ & $\begin{array}{l}\text { Control Group } \\
(N=51)\end{array}$ & $p$ value \\
\hline $10^{+0}-12^{+6}$ & $15.38(4.17)$ & $17.33(7.05)$ & 0.124 \\
\hline $\begin{array}{l}\text { Week } \\
34^{+0}-36^{+4}\end{array}$ & $21.65(5.25)$ & $19.53(8.32)$ & 0.165 \\
\hline \multicolumn{4}{|l|}{ Week } \\
\hline \multicolumn{4}{|c|}{ ALT (UI/ml) } \\
\hline & $\begin{array}{l}\text { Intervention Group } \\
(N=41)\end{array}$ & $\begin{array}{l}\text { Control Group } \\
(N=51)\end{array}$ & $p$ value \\
\hline $10^{+0}-12^{+6}$ & $27.50(10.63)$ & 28.27 (11.77) & 0.746 \\
\hline $\begin{array}{l}\text { Week } \\
\end{array}$ & \multirow{3}{*}{$22.93(9.23)$} & \multirow[b]{2}{*}{20.84 (13.49) } & \\
\hline $34^{+0}-36^{+4}$ & & & 0.407 \\
\hline \multicolumn{3}{|l|}{ Week } & \\
\hline \multicolumn{4}{|c|}{ Creat (mg/dl) } \\
\hline & $\begin{array}{l}\text { Intervention Group } \\
(N=41)\end{array}$ & $\begin{array}{l}\text { Control Group } \\
(N=51)\end{array}$ & $p$ value \\
\hline \multirow{4}{*}{$\begin{array}{l}34^{+0}-36^{+4} \\
\text { Week }\end{array}$} & \multirow[t]{2}{*}{$0.595(0.401)$} & \multirow[t]{2}{*}{$0.575(0.100)$} & 0.757 \\
\hline & & & \\
\hline & \multicolumn{2}{|l|}{ Uric Acid (mg/dl) } & \\
\hline & $\begin{array}{l}\text { Intervention Group } \\
(N=41)\end{array}$ & $\begin{array}{l}\text { Control Group } \\
(N=51)\end{array}$ & $p$ value \\
\hline $34^{+0}-36^{+4}$ & $3.526(0.787)$ & $3.262(0.672)$ & 0.218 \\
\hline Week & & & \\
\hline
\end{tabular}

nancy does not prevent from gestational diabetes but can help to control glucose levels in diabetic pregnant women [46-48]. In our study, only one woman developed gestational diabetes in the CG, and therefore no comparison could be carried out at this level.

Regarding the hepatic metabolism, it has been described that exercise increases the levels of AST and its activity [49,50]. During pregnancy, it has not been determined how exercise could affect AST and ALT yet. Our results show no statistical changes in the hepatic enzymes during pregnancy in those women exercising compared to controls.

\subsection{Renal outcomes}

At a renal level, there is no significant effect when performing mild-moderate exercise during pregnancy [8], although it is not clear 


\subsection{Study strengths and limitations}

The main strength of our study resides in being a randomized controlled study with multiple timepoints check-ups. Additionally, the guidelines for exercise followed here are internationally recommended.

On the other hand, the main limitation is the small sample size which may be reason for the lack of beneficial results and did not allow us to perform sub-group analyses. Some may argue that increasing exercise intensity may cause a greater impact, however, high-intensity exercise during pregnancy is related to adverse obstetric outcomes and therefore not recommended [52-56]. Another limitation is the increased proportion of nulliparous women compared to the general low risk pregnant population, which could represent a selection bias. However, parity has not been demonstrated as a risk factor for any of the variables studied. Finally, our study included only low-risk pregnancies and therefore our results might not be valid for a different population.

\section{Conclusions}

A regular supervised mild-moderate exercise programme during pregnancy does not impact the normal physiological changes that occur during pregnancy. However, further and larger studies are needed to confirm our findings.

\section{Acknowledgments}

We would like to thank Ana Calamaestra for her collaboration in the data management for the development of the current research, and the Obstetrics Team from Hospital Universitario de Torrejon for the collaboration in the project.

\section{Funding statement}

This research was partly funded by Research Grant provided by the Hospital Universitario de Torrejon (Madrid, Spain) and by the Universidad Politécnica de Madrid (Madrid, Spain).

\section{Supplementary materials}

Supplementary material associated with this article can be found, in the online version, at doi:10.1016/j.physbeh.2020.112863.

\section{References}

[1] World Health Organization, Global Recommendations On Physical Activity For health. [Internet], 2010 [citado 28 de enero de 2020]. Disponible en:, http:// www.ncbi.nlm.nih.gov/books/NBK305057/.

[2] al M et Perales, Efectos de un programa de ejercicio físico supervisado sobre la estructura cardiaca durante la gestacion. Ensayo clínico aleatorizado, Prog. Obstet. Ginecol. 55 (5) (2012) 209-215.

[3] C Athukorala, A R Rumbold, K J Willson, C A Crowther, The risk of adverse pregnancy outcomes in women who are overweight or obese, BMC Pregnancy Childbirth. 10 (2010) 56.

[4] R Barakat, M Perales, N Garatachea, J R Ruiz, A Lucia, Exercise during pregnancy. a narrative review asking: what do we know?, Br. J. Sports Med. 49 (21) (2015) 1377-1381.

[5] L A Haakstad, E Edvardsen, K Bø, Effect of regular exercise on blood pressure in normotensive pregnant women. a randomized controlled trial, Hypertens Pregnancy. 35 (2) (2016) 170-180.

[6] D Aune, O D Saugstad, T Henriksen, S Tonstad, Physical activity and the risk of preeclampsia: a systematic review and meta-analysis, Epidemiol. Mayo de 25 (3) (2014) 331-343.

[7] A Bonen, P D Campagna, L Gilchrist, P Beresford, Substrate and hormonal responses during exercise classes at selected stages of pregnancy, Can. J. Appl. Physiol. 20 (4) (1995) 440-451.

[8] R C Bessinger, R G McMurray, A C Hackney, Substrate utilization and hormonal responses to moderate intensity exercise during pregnancy and after delivery, Am. J. Obstet. Gynecol. 186 (4) (2002) 757-764.

[9] R C Bessinger, R G McMurray, Substrate utilization and hormonal responses to exercise in pregnancy, Clin. Obstet. Gynecol. 46 (2) (2003) 467-478.

[10] R Barakat, Y Cordero, J Coteron, M Luaces, R Montejo, Exercise during pregnancy improves maternal glucose screen at 24-28 weeks: a randomised controlled trial, Br. J. Sports Med. 46 (9) (2012) 656-661.

[11] M Brik, I Fernández-Buhigas, A Martin-Arias, M Vargas-Terrones, R Barakat, B Santacruz, Does exercise during pregnancy impact on maternal weight gain and fetal cardiac function? A randomized controlled trial, Ultrasound Obstet. Gynecol. 53 (5) (2019) 583-589.
[12] A C O G Committee Opinion No. 650, Physical activity and exercise during pregnancy and the postpartum period, Obstet. Gynecol. 126 (6) (2015) e135-e142.

[13] M Perales, I Refoyo, J Coteron, M Bacchi, R Barakat, Exercise during pregnancy attenuates prenatal depression: a randomized controlled trial, Eval. Health Prof. 38 (1) (2015) 59-72.

[14] R Barakat, M Pelaez, R Montejo, M Luaces, M Zakynthinaki, Exercise during pregnancy improves maternal health perception: a randomized controlled trial, Am. J. Obstet. Gynecol. 204 (5) (2011) 402 .e1-7.

[15] R Barakat, M Pelaez, Y Cordero, M Perales, C Lopez, J Coteron, et al., Exercise during pregnancy protects against hypertension and macrosomia: randomized clinical trial, Am. J. Obstet. Gynecol. 214 (5) (2016) 649 .e1-8.

[16] M E O'Neill, K A Cooper, C M Mills, E S Boyce, S N Hunyor, Accuracy of Borg's ratings of perceived exertion in the prediction of heart rates during pregnancy, Br. J. Sports Med. Junio de 26 (2) (1992) 121-124.

[17] R Ramírez-Vélez, A C Aguilar de Plata, M M Escudero, I Echeverry, J G Ortega, B Salazar, et al., Influence of regular aerobic exercise on endothelium-dependent vasodilation and cardiorespiratory fitness in pregnant women, J. Obstet. Gynaecol. Res. 37 (11) (2011) 1601-1608.

[18] M Perales, A Santos-Lozano, F Sanchis-Gomar, M Luaces, H Pareja-Galeano, N Garatachea, et al., Maternal cardiac adaptations to a physical exercise program during pregnancy, Med. Sci. Sports Exerc. 48 (5) (2016) 896-906.

[19] M Perales, et al., Efectos de un programa de ejercicio físico supervisado sobre la estructura cardiaca durante la gestacion. ensayo clínico aleatorizado, Prog. Obstet. Ginecol. 55 (5) (2012) 209-215.

[20] D S Genest, S Falcao, J Gutkowska, J L Lavoie, Impact of exercise training on preeclampsia: potential preventive mechanisms, Hypertension 60 (5) (2012) 1104-1109.

[21] S Meher, L Duley, Exercise or other physical activity for preventing pre-eclampsia and its complications, Cochrane Database Syst. Rev. (2) (2006) CD005942.

[22] L K Callaway, J B Prins, A M Chang, H D McIntyre, The prevalence and impact of overweight and obesity in an Australian obstetric population, Med. J. Aust. 184 (2) (2006) 56-59.

[23] M Vargas-Terrones, T S Nagpal, R Barakat, Impact of exercise during pregnancy on gestational weight gain and birth weight: an overview, Braz. J. Phys. Ther. 23 (2) (2019) 164-169.

[24] J M Dodd, R M Grivell, A M Nguyen, A Chan, J S Robinson, Maternal and perinatal health outcomes by body mass index category, Aust. N Z J. Obstet. Gynaecol. 51 (2) (2011) 136-140.

[25] S Y Chu, W M Callaghan, C L Bish, D D'Angelo, Gestational weight gain by body mass index among us women delivering live births, 2004-2005: fueling future obesity, Am. J. Obstet. Gynecol. 200 (3) (2009) 271 .e1-7.

[26] J Smith, K Cianflone, S Biron, F S Hould, S Lebel, S Marceau, et al., Effects of maternal surgical weight loss in mothers on intergenerational transmission of obesity, J Clin Endocrinol Metab. 94 (11) (2009) 4275-4283.

[27] J G Kral, S Biron, S Simard, F S Hould, S Lebel, S Marceau, et al., Large maternal weight loss from obesity surgery prevents transmission of obesity to children who were followed for 2 to 18 years, Pediatrics 118 (6) (2006) e1644-e1649.

[28] L L Birch, A K Ventura, Preventing childhood obesity: what works?, Int. J. Obes. 33 (Suppl 1) (2009) S74-S81.

[29] Z M Ferraro, Q Qiu, A Gruslin, K B Adamo, Excessive gestational weight gain and obesity contribute to altered expression of maternal insulin-like growth factor binding protein-3, Int. J. Womens Health 5 (2013) 657-665.

[30] A Ornoy, Prenatal origin of obesity and their complications: gestational diabetes, maternal overweight and the paradoxical effects of fetal growth restriction and macrosomia, Reprod. Toxicol. 32 (2) (2011) 205-212.

[31] K M Godfrey, A Sheppard, P D Gluckman, K A Lillycrop, G C Burdge, C McLean, et al., Epigenetic gene promoter methylation at birth is associated with child's later adiposity, Diabetes 60 (5) (2011) 1528-1534.

[32] Z B Yu, S P Han, G Z Zhu, C Zhu, X J Wang, X G Cao, et al., Birth weight and subsequent risk of obesity: a systematic review and meta-analysis, Obes. Rev. 12 (7) (2011) 525-542.

[33] W Kabiru, B D Raynor, Obstetric outcomes associated with increase in bmi category during pregnancy, Am. J. Obstet. Gynecol. 191 (3) (2004) 928-932.

[34] M Pelaez, S Gonzalez-Cerron, R Montejo, R Barakat, Protective effect of exercise in pregnant women including those who exceed weight gain recommendations: a randomized controlled trial, Mayo Clin Proc. 94 (10) (2019) 1951-1959.

[35] R Barakat, M Pelaez, Y Cordero, M Perales, C Lopez, J Coteron, et al., Exercise during pregnancy protects against hypertension and macrosomia: randomized clinical trial, Am. J. Obstet. Gynecol. 214 (5) (2016) 649 .e1-8.

[36] M F Mottola, I Giroux, R Gratton, J A Hammond, A Hanley, S Harris, et al., Nutrition and exercise prevent excess weight gain in overweight pregnant women, Med. Sci. Sports Exerc. 42 (2) (2010) 265-272.

[37] L A Haakstad, K Bø, Effect of regular exercise on prevention of excessive weight gain in pregnancy: a randomised controlled trial, Eur. J. Contracept. Reprod. Health Care 16 (2) (2011) 116-125.

[38] S Phelan, Pregnancy: a «teachable moment» for weight control and obesity prevention, Am. J. Obstet. Gynecol. 202 (2) (2010) 135 .e1-8.

[39] C Amezcua-Prieto, P Lardelli-Claret, R Olmedo-Requena, J Mozas-Moreno, A Bueno-Cavanillas, J J Jiménez-Moleón, Compliance with leisure-time physical activity recommendations in pregnant women, Acta Obstet. Gynecol. Scand. 90 (3) (2011) 245-252.

[40] C M Olson, M S Strawderman, Modifiable behavioral factors in a biopsychosocial model predict inadequate and excessive gestational weight gain, J. Am. Diet. Assoc. 103 (1) (2003) 48-54.

[41] J F Clapp, Morphometric and neurodevelopmental outcome at age five years of the offspring of women who continued to exercise regularly throughout pregnancy, J. Pediatr. 129 (6) (1996) 856-863.

[42] N Oostdam, J Bosmans, M G Wouters, E M Eekhoff, W van Mechelen, M N van Poppel, Cost-effectiveness of an exercise program during pregnancy to prevent 
[43] A Y Cheng, Committee CDACPGE., Canadian diabetes association 2013 clinical practice guidelines for the prevention and management of diabetes in Canaa. introduction, Can J. Diabetes. 37 (Suppl 1) (2013) S1-S3.

[44] L A H Haakstad, K Bø, Effect of regular exercise on prevention of excessive weight gain in pregnancy: a randomised controlled trial, Eur. J. Contracept. Reprod Health Care. Abril de 16 (2) (2011) 116-125.

[45] A L Deierlein, A M Siega-Riz, K R Evenson, Physical activity during pregnancy and risk of hyperglycemia, J. Womens Health Larchmt. 21 (7) (2012) 769-775.

[46] S Han, P Middleton, C A Crowther, Exercise for pregnant women for preventing gestational diabetes mellitus, Cochrane Database Syst. Rev. (7) (2012) CD009021.

[47] S M Ruchat, M F Mottola, The important role of physical activity in the prevention and management of gestational diabetes mellitus, Diabetes Metab. Res. Rev. 29 (5) (2013) 334-346.

[48] Y N Yin, X L Li, T J Tao, B R Luo, S J Liao, Physical activity during pregnancy and the risk of gestational diabetes mellitus: a systematic review and meta-analysis of randomised controlled trials, Br. J. Sports Med. 48 (4) (2014) 290-295.

[49] H Ohno, H Watanabe, C Kishihara, N Taniguchi, E Takakuwa, Effect of physical exercise on the activity of got isozyme in human plasma, Tohoku J. Exp. Med. 126 (4) (1978) 371-376.

[50] P Lijnen, P Hespel, E Vanden Eynde, A Amery, Biochemical variables in plasma and urine before and after prolonged physical exercise, Enzyme 33 (3) (1985) 134-142.
[51] D DG, L PWR, Effect of exercise on protein utilization during pregnancy [abstract], Can J. Appl. Sport Sci. (1986) 11P.

[52] M Madsen, T Jørgensen, M Jensen, M Juhl, J Olsen, P Andersen, et al., Leisure time physical exercise during pregnancy and the risk of miscarriage: a study within the danish national birth cohort, Bjog. 1 de Noviembre de 114 (11) (2007) 1419-1426.

[53] K Bø, R Artal, R Barakat, W Brown, M Dooley, K R Evenson, et al., Exercise and pregnancy in recreational and elite athletes: 2016 evidence summary from the ioc expert group meeting, Lausanne. part 2-the effect of exercise on the fetus, labour and birth, Br. J. Sports Med. 1 de Noviembre de 50 (21) (2016) 1297-1305.

[54] A M Jukic, K R Evenson, J L Daniels, A H Herring, A J Wilcox, K E Hartmann, A prospective study of the association between vigorous physical activity during pregnancy and length of gestation and birthweight, Matern. Child Health J. 16 (5) (2012) 1031-1044.

[55] K Bø, R Artal, R Barakat, W J Brown, G A L Davies, M Dooley, et al., Exercise and pregnancy in recreational and elite athletes: 2016/2017 evidence summary from he IOC expert group meeting, Lausanne. part 5. recommendations for health professionals and active women, Br. J. Sports Med. Septiembre de 52 (17) (2018) 1080-1085.

[56] H N Soultanakis, R Artal, R A Wiswell, Prolonged exercise in pregnancy: glucose homeostasis, ventilatory and cardiovascular responses, Semin Perinatol. Agosto de 20 (4) (1996) 315-327. 